\title{
Development of the Viable System Model of Partner Relationship Management of the Company
}

\author{
Iryna Fedotova $^{1}$, Volodymyr Shynkarenko ${ }^{1}$, Oksana Kryvoruchko $^{1}$ \\ ${ }^{1}$ Kharkiv National Automobile and Highway University, Kharkiv \\ *Corresponding author E-mail: irina7vf@gmail.com
}

\begin{abstract}
This paper considers the main instruments for relationship management between the company and different partners. The purpose of the study is to improve the theoretical foundations of the development of a system of total relationship management of the company with the main groups of interaction actors, taking into account relationships with all groups of partners of the company. The model of the relationship management system of the company on the basis of methodical apparatus of cybernetic modeling of viable systems is proposed. The model of the relationship management system of the company is presented as an entity (a metasystem) and an object of management (operating element), which is proposed in the form of relationship management processes with main groups of partners. The system of inter-company interactions, which reflects the development of individual relationship with a certain partner, is presented. Based on the structural-level and metasystem approaches, key levels and structure of enterprise relationships are identified. Five levels of relationship between the company and its partners - element, component, subsystem, system-wide, and metasystem levels are identified. These levels are presented in the form of recursive structure of the viable model of relationship management system of the enterprise.
\end{abstract}

Keywords: Actors of interaction; partner; relationship management; relationship; viable system.

\section{Introduction}

In the conditions of high level of instability and uncertainty of the organizational and economic environment, mechanisms for increasing the stability, effective management of enterprises, and development of new relations should be developed. The increase of possible options of interaction in the modern socio-economic environment requires the expansion of the methodological apparatus and tools for studying the relationship between enterprises.

The main categories of interaction and relation between economic entities are most fully studied in the relationship marketing. Within this approach, an attempt was made to describe and define the laws under which the mechanism of interaction between market actors works. With the increasing interest of scientists and practitioners in this field of knowledge, a variety of interpretations of the mechanism of interactions, interpretations of the nature of relationship emerged. It was found that relationship at different levels of interaction is far from homogeneous. The researchers faced the task of constructing and substantiating the types of various relationship that arise between different economic entities, identifying the main groups of this relationship. All of the above suggests the need for both researchers and practitioners to reproduce more closely the mechanism of market interaction and the levers of management of this mechanism.

In the general sense, the interaction is seen as the exchange of matter, energy, information between two or more objects (subjects) that is regular (in natural systems) or irregular (in artificial formations), but directed. Interactions between enterprises manifest themselves in the form of exchanges of information, financial resources, goods, resources, technologies and consist of a multitude of individual interaction acts. Interaction between partners in $\mathrm{B} 2 \mathrm{~B}$ market is the main process in the formation of relationship.
Relationship is the way in which two or more companies, countries, or people behave towards each other.

The enterprise as a complex social and economic system, in the course of its functioning, forms relationship with various types of entities of the internal and external environment (workers, customers, suppliers, contractors, state bodies, etc.). The nature of the interaction of actors determines the level of viability and competitiveness of the enterprise.

Achieving competitive advantages in the long run depends largely on how the company builds relationship with its customers, suppliers, contractors and other actors of interaction. These actors of interaction become full members of the chain of value creation and directly affect the strategy of all enterprises involved in the interaction. The transition of companies to a new type of relationship in B2B field requires the development of a relationship model between the company and its partners, which would link the entire relationship complex with different actors of interaction.

\section{Literature Review and Theoretical Founda- tion}

Problems of the methodology of relations and interactions between enterprises in terms of marketing relationships (or relationship management) are highlighted in the papers of the authors [116]. The most acute contradictions among scientists lie in determining the main function of the marketing relationship system and its orientation, and what features and processes of the enterprise it affects. It should be noted that only a small number of scientific researches are devoted to the development of a total relationship system between enterprises with different groups of partners. Analyzing the papers of the authors, there is no unity of thought about 
the development of relationship between the enterprise and partners, most authors consider the relationship management with different actors of interaction. One group of authors [1-4] focuses on the relationship with only one group of actors of interaction, while other authors J. Egan [5], Ph. Kotler [6], R. Morgan and S. Hunt [7] and others [8-14] include different groups of partners as the members of relationship into the relationship system, they consider relationship with customers (consumers), distributors, suppliers, employees and other partners.

In the theory and practice of marketing and management of relationship, various automated management tools have been developed. The most common Customer Relationship Management (CRM) system is no longer innovative. Scientists have proposed other system of electronic Business Relationship Management (eBRM) for marketing technology of relationship management Internet-communication based system for Customer Relationship Management (CRM), Partnership Relationship Management (PRM), Human Resources Management (HRM) and Stakeholder Relationship Management (SRM). eBRM tools will link interpersonal communication channels, partner channels, business functions and data.

The tools of relationship management between the company and suppliers - Supplier Relationship Management (SRM) - have already been extensively studied. In recent years, more and more attention is given to the relationship management with suppliers, taking into account the interests of end-users (CRM) - Supply Chain Management (SCM) [15].

However, with the increase in the number of companies with a developed partner network, there is a need to increase not only the efficiency of the relationship with customers and suppliers, but also to create the complex systems of interaction between partners. Therefore, in the last decades, special programs and concepts for Partner Relationship Management (PRM) [16] began to appear. Partner Relationship Management (PRM) is a business strategy for selecting partners and relationship management with them in order to increase their efficiency and value for the enterprise. In particular, PRM involves optimizing work with partners to achieve their best result in transactions with common customers and finally the satisfaction of the end-user and partner. E. Gummesson [9] proposed the concept of Total Relationship Marketing (TRM), which emphasizes the long-term relationship between manufacturer and consumer and obtaining long-term profits with the involvement of any market forces. The relationship marketing by E. Gummesson [9] can be visibly represented through 30 types of business relationship "30R", grouped into four classes: classic market relationships; special market relationships; mega relationships; nano relationships.

Most authors consider types and kinds of relationships depending on the similarity of interaction with partners. R. Morgan and S. Hunt [7] offer a classification of companies' relationships from the point of view of the central company, dividing the relationship exchanges of the central company into partnerships with suppliers, horizontal partnerships, partnerships with customers and internal partnerships, and, as a result, distinguish 10 types of partnerships. Other authors used a systematic approach and considered the level of relationship with partners, depending on the level of relationship management of the central company. The classification of the relationship levels was proposed by T. Ritter, I.F. Wilkinson and W.J. Johnston [10]: individual players, dual relationships, relationship portfolio, related relationships (relationships with consumers of consumers and suppliers of suppliers) and networks. Authors S.P. Kushch, A.A. Afanasiev [11] identified four levels of relationships: individual relationships with suppliers and customers, portfolio of relationships, central network, and field network. However, the proposed relationship models are limited only by the actors included in the chain of value formation. The authors assume only consistent interaction and do not structure the relationship system between enterprise networks.

E.V. Isaeva [12] expanded the composition of the interaction actors of the enterprise, the author proposed to consider three levels of enterprise relationships: intra- and inter-company relationship of employees of actors; relationship with market entities that are related to the enterprise; relationship with the market entities, with which the enterprise is not involved in interaction, but may interact in the future. This model of the relationship system between enterprises considers a large number of external and internal interaction actors of the enterprise. It allows more complete representation of inter-company networks of enterprises, but it is generalized, and it does not represent the structure of the relationship and coordination of actors in the network.

Another author, M. Zineldin [13], proposed Total Relationship Management (TRM) approach in terms of the development of a relationship system, which focuses on the complex of external and internal factors of the enterprise, quality and relationship with different groups of partners (clients, suppliers, distributors, employees). He highlighted seven principles according to which the organization should adopt the philosophy of total strategic relationship management and proposed TRM house of the enterprise. This approach allows to coordinate all enterprise activities, including internal and external network relationships, interaction and collaboration, as well as all activities related to the search, retention, strengthening and satisfaction of customers.

The generalization of the results of the performed research has shown that among scientists there is no unity of opinion regarding the composition and content of partner relationship management. The lack of a systematic approach to partner relationship management does not allow the enterprise to use on the full scale its available opportunities to organize effective interaction with its partners.

Thus, the purpose of the paper is to improve the theoretical foundations of the system of total relationship management between the enterprise and the main groups of actors of interaction and to create a multilevel system of relationship between the enterprise and its partners in terms of system and structural-level approaches.

\section{Results and Discussion}

In order to determine the level of relationship between enterprises and internal and external partners, it is necessary to consider a multilevel enterprise management system. The system shall be recursive, that is, one system contains other systems. They can be simulated using identical cybernetic descriptions of different levels of the hierarchy of the system. Thus, at each level of enterprise recursion, different levels of partner relationship are formed. In the conditions of dynamic environment, special attention shall be paid to the development of a viable relationship management system of the enterprise.

The further development and use of the cybernetic viable system model (VSM) of the company, proposed by S. Beer [17], is of great importance. S. Beer described the model as a neurocybernetic model, the prototype of which the architecture of the central nervous system of a human is served, where the units work autonomously in the usual conditions and "dictatorship of the center" switches on only in extreme circumstances. S. Beer proved the feasibility of the proposed model based on the basic laws and principles of cybernetics.

The viable system model consists of three groups of elements: the operating element, the metasystem and the environment. The operating element and the metasystem were divided by the author into five interacting systems. In order to be viable, the company, like a living organism, needs five management levels (subsystems) that can be reflected as aspects of the organizational structure. Each level has contractual authorities on its autonomy and works within its competence. The flow of information goes from the bottom up, gradually filtering the extra details. The levels of control are included depending on the need.

When simulating a viable system and displaying its integrity, the graphical method is used mainly [17-19], which is clearly shown in Figure 1. 


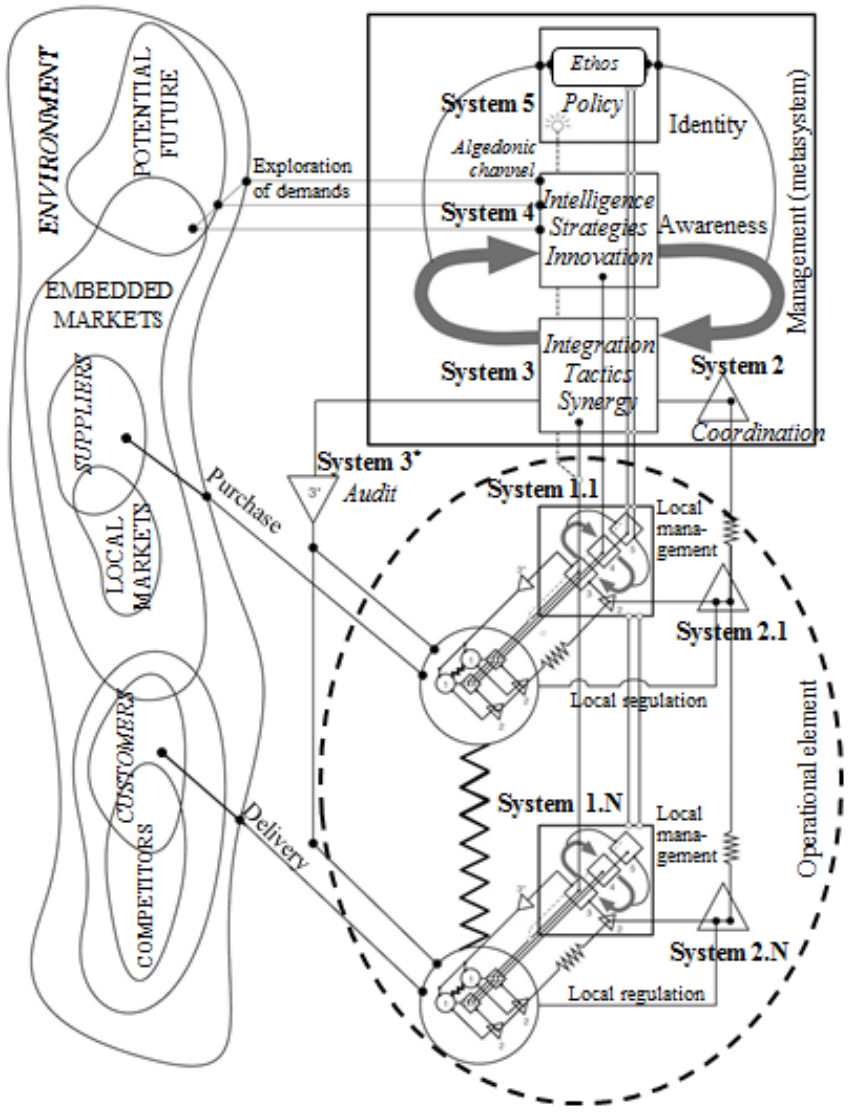

Fig. 1: Viable System Model adapted from S.Beer [17] and J.Rios [18].

In the viable system model, there are three elements - the environment, the operating element and the meta-system, as well as various relationships (interactions) between them. System 1 in the viable system model provides several main activities $(1.1, \ldots, 1 . \mathrm{N})$ and is designed to manage the unit in response to the scheduled directives and instructions coming from above, to respond to direct demands of the outside world in relation to it and be ready to meet needs of neighboring units.

Systems 2 - 5 form the so-called meta-system. They are not viable themselves, they are not centers for value added and do not form an independent organization. These are the elements of the structure that are intended to maintain the organization, for its selfregulation in the event of changes in external circumstances (external environment) and internal situation (technological operations).

System 2 is a system that brings in intermediate results of all systems. It participates in the work of systems 1 and 3 and is an interface that is responsible for linking the work of the regulation centers of units and the regulation center of the enterprise.

System 5 is a mechanism for policy development and decisionmaking (it is owned by the top management of the organization), designed to manage both internal and external events.

System 3 already refers to the top management, and its interaction with system 1 is related to the understanding of the subordinate role of units, with the management right to limit the autonomy of units in order to synergy. System 3 explains top-level policy, coordinates the division of effort and resources between units, conducts audits, maintaining, in general, the stability of autonomous work of the units.

System 4 provides the downward transfer of volitional requirements of the top management, and also includes channels for forwarding up the information needed for management of the entire company. The data on the state of the environment also pass through it. This system, above all, is responsible for the effective planning of the enterprise.

Vertical information channels, implementing corporate linking, shall deal with a variety of environments and operations, while the audit unit "System 3 *" is intended to cover the possible imbalance in management diversity and variety of technological operations and environments.

In the broad sense, systems 1 to 3 relate to tactical and operational activities of the organization (in relation to business structures current production and commercial activities), and system 4 cares about a strategic response to external environmental challenges. System 5 is responsible for the balance between current activities and the strategy for future development, formulating policy guidelines that ensure the viability of the organization. From the Figure 1 it can be seen that:

- operations are the same as system 1;

- the meta-system consists of systems 2, 3, 4 and 5;

- system 4 interacts with the external environment, i.e. it deals with the analysis of actions and forecasting;

- systems 2 and 3 interact with the internal environment (operations).

The task of the meta-system is to ensure cohesion and unity, stability, optimization, future planning, adaptation to the changing environment. It can be seen from the model that a large operating element also has a structure similar to the original and represented by several smaller operating elements. Obviously, the enclosed operating modules (operations) are similar by their structure to the main operation in which they are included. This illustrates the principle of recursion, which is one of the key concepts of VSM. It is applied at all levels of VSM, where operations consist of smaller, viable systems and are included in a large, viable system. VSM provides for the organization of a number of operating units and metasystems united to work together as an integrated, harmonious whole.

The model also presents the external environment. The presence of the external environment reflects the scope of the system, without which it is impossible to take into account the base of internal interactions of the organization.

Figure 1 presents the system of external and internal relationships. Internal relationships are formed between the personnel of certain units of the enterprise (internal partners). External relationships arise when the personnel of the company interact with representatives of the environment (consumers, suppliers, contractors and other partners).

When developing a relationship management model between the company and partners on the basis of the concept of viable systems, it is advisable to proceed from the main business processes of the enterprise, i.e. to use process management. It represents a view of the enterprise as a related set of business processes, which are grouped by major groups of partners of the enterprise. Some authors $[7,8]$ distinguish the following groups of actors (partners) of relationship of the enterprise: internal partners (personnel, owners, units); consumers (physical entities, legal entities); suppliers (of goods and services); contractors (in sales of goods or services, marketing ones); contact audiences (government, lending financial institutions, media, civilian groups, local audiences, etc.). In addition, it is necessary to take into account relationship with competitors of the enterprise; they to some extent affect the development of other types of relationships. Existing and potential competitors are also a priority direction of the marketing interactions of the enterprise, as their actions can influence the selection of channels of movement of goods, consumer audiences and the level of market power of the manufacturer. The listed partners play a significant role in development of total partner relationship of the company, so there is a need to integrate them into specific groups and to identify separate processes for managing these relationships.

Figure 2 proposes a relationship management system of the enterprise, which presents the processes of relationship development with different types of partners. It is proposed to present system 1 not as functional units of the enterprise, but as the basic processes of interaction with certain groups of partners. 


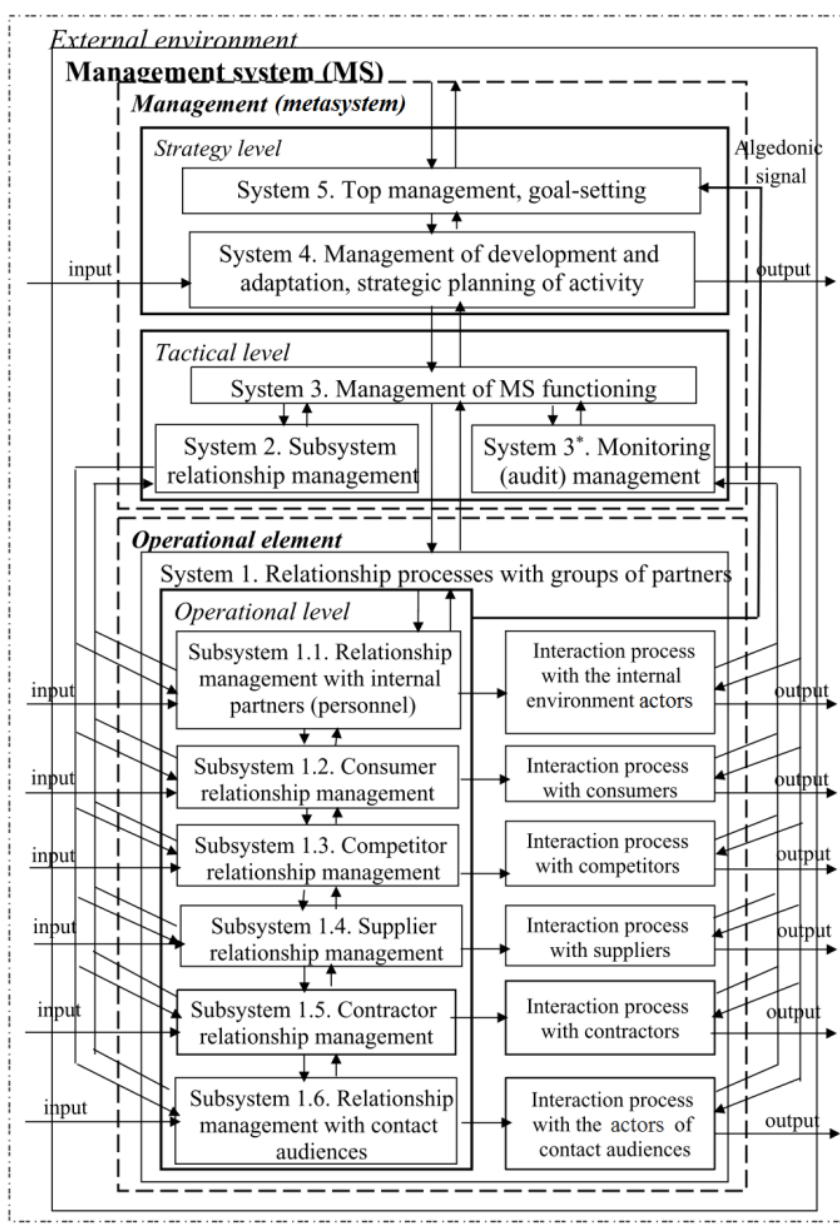

Fig. 2: The model of the relationship management system of the company with the main partners.

They are divided into six subsystems that are responsible for managing the relationship processes between the enterprise and its internal partners (personnel), consumers, competitors, suppliers, contractors and contact audiences. In turn, business processes of management and development will be presented in the metasystem of the model (systems 2 - 5).

The viable relationship management system of the enterprise contains the following elements: the external environment, enterprise management system, consisting of the management meta-system the management entity and the operating element - the management object. The meta-system has two management levels: strategic and tactical. The system of strategic management includes two subsystems: the system 5 of the top management and system 4 of development and adaptation management.

System 5 is responsible for goal-setting, develops strategic goals, mission, vision and policy, performs the basic functions of management: planning, organizing, governance, motivation, control, system 4 - for the decisions related to strategic planning, development models and evaluation criteria, adaptation to the environment, it provides competitive analysis, identifies strategic issues, problems and opportunities.

The structure of the subsystem of goal-setting includes the owners of the enterprise, board of directors or administration, depending on the legal form. The structure of the subsystem 4 includes the top management of the enterprise, which forms the directorate of development.

The level of tactical management corresponds to direct management activity, which includes the development of tactical decisions that contain both parametric (quantitative) and stimulating (qualitative) influences, and consists of three subsystems.

System 3 - operation management, optimizes total functioning of the system, coordinates the distribution of efforts and resources between subsystems, provides the necessary synergy. On its basis, the directorate of the current activity is formed, which includes various managers by the fields of activity, deputy directors or heads of departments.

System $3^{*}$ - audit management, monitoring, control and internal audit. The control over the implementation of the plans includes an assessment of the indicators characterizing the development of various fields of activity, as well as, if necessary, setting the task for lower subsystems to eliminate differences between planned and actual indicators.

System 2 - interaction management, it regulates the interaction of units, provides stimulation or deceleration of their functioning, i.e. it is the center of regulation of the enterprise and it summarizes the interim results of the work of all subsystems 1 . At the subsystem level 2, business process managers approve and coordinate decisions taken.

In cases where direct coordination is not possible, due to the emergence of a conflict of interest between different business processes, the coordination takes place at a level of system 3 , under the direction of the directorate of current activities. However, for it there is no comparison with units or officials of the enterprise, so it is likely to be a management business process. This business process is a set of procedures for coordinating operational results and decisions taken at the levels of subsystems 1 , as well as procedures for transferring aggregated information to a higher level of management.

The object of management implements business processes that ensure the fulfillment of the main goal of the enterprise operation. System 1 is presented in the form of six groups of processes of relationship between enterprises and partners: consumers, suppliers, contractors, staff, competitors, actors of contact audiences (state bodies, mass media, financial institutions, local community, etc.). Each process presents input and output parameters, respectively, the resources and results of each business process. At the level of system 1, managers of business processes carry out their business in their areas of activity. The interaction and interconnection between subsystems passes through decision makers, with the same managers taking part simultaneously in several levels of management.

Between operational and strategic levels of management there is a connection used in the cases where senior managers directly receive information about the work of specific units of the lower level, and is called the algedonic signal. Algedonic signals are signals generated to alert management modules about the need to interfere with system activities that rise through recursion levels when the actual performance failed or exceeds the system's capabilities. The transition from functional approach to management, used in the concept of viable systems, to a more progressive process approach, will enhance the universality of the concept being developed.

According to the set goals and tasks in the field of management of relationship between the company and its partners in terms of the system approach, the management subsystem (the management entity) shall have an influence on the management object - the process of partner relationship, and to supply it with goals and resources. The control subsystem shall, on the one hand, ensure the internal integration of the components of subsystems, and, on the other hand, provide adaptation to changes in the environment. Since the proposed viable partner relationship management system (Figure 2) is a recursive system, each subsystem of the operating element is repeated in a similar way with the total management system. Each subsystem of the relationship management of the company with consumers, suppliers, contractors and other entities will have the form of a separate cybernetic model of the lower level management system.

Internal partner relationships with the enterprise are presented in the form of interaction and communication of owners, personnel of the enterprise in the process of performing their functions.

Relations between the enterprise and the economic entities of the environment (consumers, suppliers, contractors, etc.) can be represented in the form of the interaction of two separate dynamic systems. 
From the point of view of the system approach, the process of relations between the enterprises and a certain partner in the form of a system of interaction of objects of marketing activity was considered in detail by V.G. Shynkarenko [20]. The author notes the presence of two objects of marketing activity that interact with the process of matching the demand and supply of services through the feedback system. The approach involves the interaction of two open enterprise and client management systems.

Using the same principle, it is possible to present a total system of relationship between enterprises with different types of external partners (Fig. 3). The enterprise in the process of its activities interacts with different partners, at one and the same time can act as a producer and consumer. In the proposed system of intercompany cooperation it is feasible to consider situations when the company provides goods and services (acts as a producer), and receives certain goods and services (acts as a consumer).

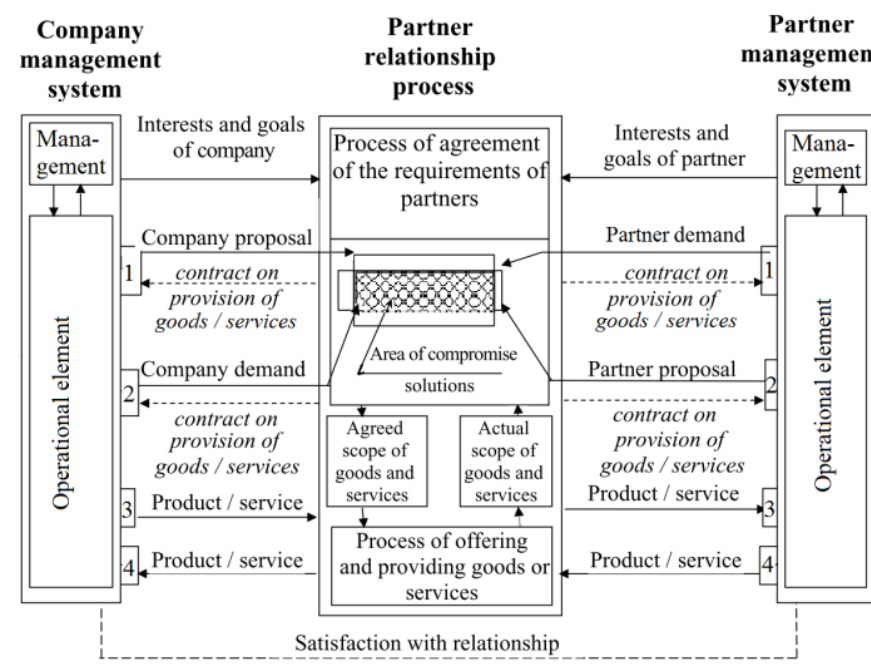

Fig. 3: Total system of interaction between the company and the partner.

Figure 3 presents a generalized process of relationship between the enterprise and the certain partner, with the contact points of the objects of management (business processes) of each of them, deployed in space and time.

The contact points 1 and 2 are the processes of matching demand and supply of goods or services, correcting them through the feedback system. At the stage of supply of goods or services (contact points 3 and 4), the quality of goods and services is demonstrated and the requirements of scope, price and quality are met.

In the interaction of the enterprise with the consumers, active contact points are 1 and 3 , as the company sells goods or services to the client. In the relationship with other groups of partners (suppliers, contractors, etc.) contact points 2 and 4 are activated as the enterprise receives the relevant services or goods. This system of inter-company interaction reflects the development of individual relationships with the certain partner.

The proposed relationship management system between the company and partners will allow decision makers to coordinate the adoption and implementation of decisions on the functioning of the enterprise at different levels of management.

Complex control systems are characterized by a clearly expressed hierarchy, and at the upper levels inevitably come to a certain set of local management systems. Each level of management is characterized by its specific relationship. According to systemology, there are two ways to integrate systems: the development of a structured system or a meta-system. In the first case, the system is divided into subsystems, which in turn are divided into subsystems of the second level, the third level, and so on. In the second case, the system is formed on the basis of the substitution rule, when from a set of systems at any moment one or a certain group of functioning systems is selected. In the methodology of the system approach, as is known, there is an important concept of metasystem level of organization, the concept of meta-systematicity in general. Meta-system level is not only hierarchically higher, but also through it the system interacts with other systems and develops in such interactions. The system approach is gradually transformed into a meta-system approach [21, 22]

In general, this is a multi-level structure of the interacting elements of a particular subject area, united in a five level subsystems in order to achieve a single goal (target function), the higher of which is the meta-system level. Meta-system approach is not limited to considering a phenomenon as a separate system. It provides an analysis of those systems that are located next to the given or at the level above it, with which the investigated system interacts.

To determine the relationship between the enterprises, it is proposed to use the criterion for the differentiation of levels in accordance with the meta-system approach [23]. In this approach, we select the integrative levels of relationship between enterprises in the structure of a complex whole:

- Element level, which includes the structural simplest constituent elements of the system. The constituent elements are workers who perform certain operations, actions, and between them there is a relationship, necessary in the process of functioning of the enterprise;

- Component level - components consist of elements possessing specific properties of this system. In this case, the components are people's groups or structural units of the enterprise that perform certain functions or business processes. At this level, relationship between the structural units or teams within the enterprise are formed;

- Subsystem level - components are grouped in the subsystem as part of the system, they can become independent systems. At this level, the integration of structural units, functions, types of activities and flows of various types of resources within the subsystem of the individual enterprise, which can function as an independent open system, is formed. The enterprise cooperates with various types of partners in the process of its activities, forms a management system of these relationships. Each partner also represents a separate subsystem in the external environment;

- System-wide level - in other way, it is proposed to call it the integrity level, where the phenomenon is represented in its entirety. This level forms a large system of inter-organizational network management, which covers manufacturing enterprises, contractor, trade, transport and financial organizations of different departments, the infrastructure of the economy of an individual country or group of countries. Thus, at this level, interaction between subsystems - partners of the enterprise (clients, suppliers, contractors, etc.) is formed. In this system, relationships of interacting partner enterprises, integrated into a single network, are formed;

- Meta-system level - it includes systems that are located next to a given one or of higher level, between these systems there is interaction and mutual influence. Meta-system level allows solving current and long-term tasks of harmonization of the whole set of relationships between organizational networks among themselves, gradually moving into a higher-level relationship between the branches of the country, various countries at the national and interstate level.

Figure 4 shows the vertical deployment of the enterprise relationship system and its distribution at the structural levels, which are the recursion levels of VSM model.

When deploying the vertical complexity of the enterprise relationship, the less complex levels of the organization interact with the relevant parts of the environment. That is, the external environment is divided into sub-environments, which represent certain partners of the enterprise. Vertical deployment will determine with what type of environment the enterprise faces and develops the relationship. Each level of recursion is a viable system that is an integral part of a viable higher-level system.

Let's consider in more detail these levels of partner relationship of enterprise (Fig. 4).

Level 1 is a metasystem level, achieved by the enterprise when it becomes a part of the inter-organizational network as a single system, and it enters into a relationship with another network. 


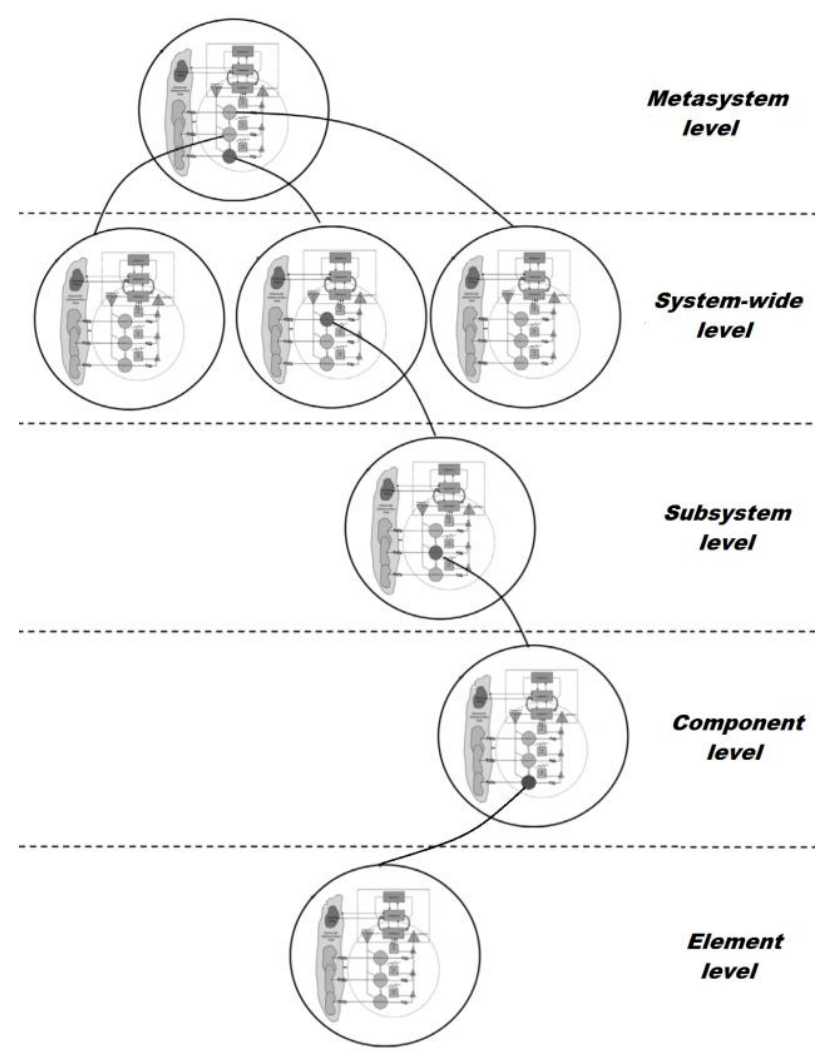

Fig. 4: Recursive structure of the viable model of the relationship management system of the company (adapted from J. Rios [18]).

Level 2 is called system-wide level, and it is a complex system of relationships, which is formed either within the development of individual relationship with each partner, or inside the interorganizational network (inside various forms of integration). At this level, stable formal and informal links are formed between enterprises that are united to achieve common goals.

Level 3 of recursion is the subsystem level, the whole complex of relations between the enterprise and its partners is considered here, the example of the model of relationship system is shown in Fig. 2. Level 4 corresponds to the component level of relationship, when the workers are grouped in teams (departments or structural units), and for the joint implementation of certain processes or business processes of the enterprise. At this level, the processes of interaction with each partner of the enterprise are formed.

Level 5 of recursion is the lowest and corresponds to the elemental level of the relationship. Relationships are formed between individual executors of certain operations or actions, both inside the enterprise and with the staff of the partners.

Thus, based on the meta-system approach, the main levels and structure of the relationship between the enterprise and the partners are determined. The larger and stronger the company is and the more partners and interconnections it has, the more complicated relationships it develops and rises to higher levels of recursion. Element and component levels reflect to a greater degree the relationship within the enterprise. Other levels focus more on the relationship development between the company and its partners in the external environment.

\section{Conclusion}

The proposed model of the relationship management system of the enterprise with the main partners is developed using the principles of building the viable systems and allows to compare the needs and capabilities of the enterprise and realize its potential, to ensure the stability of functioning and adaptation to the conditions of a changing environment. The relationship management system of the enterprise has a targeted cyclic nature, allows in-time use of the received information in the management system, and taking into account the interests of both the company itself and its partners, which will enable the improvement of their relationship.

With the help of the proposed model, decision makers will be able to coordinate the adoption and implementation of decisions on the operation of the enterprise at different levels of management. Consideration and coordination of the enterprise's relationship with each group of partners as a uniform system will allow to obtain synergistic effect from the relationship.

\section{References}

[1] Newell F., Why CRM Doesn't Work: How to Win By Letting Customers Manage the Relationship, Kogan Page, London, (2003).

[2] Payne A., Handbook of CRM: Achieving Excellence in Customer Management, Elsevier, (2006).

[3] Sabine Moeller (2006), Martin Fassnacht and Sonja Klose, "A Framework for Supplier Relationship Management (SRM)”, Journal of Business-to-Business Marketing, Vol. 13(4), pp: 69-94, available online: http://doi.org/10.1300/J033v13n04_03.

[4] Merlin Stone, Neil Woodcock and Liz Machtynger, Customer relationship marketing: get to know your customers and win their loyalty, Kogan Page in association with Marketing magazine, London, (2000).

[5] Egan J, Relationship Marketing: Exploring Relational Strategies in Marketing, Financial Times/ Prentice Hall, (2011).

[6] Philip Kotler, Kevin Lane Keller, A Framework for Marketing Management, Pearson, (2015).

[7] Morgan RM \& Hunt ShD (1994), "The commitment-trust theory of relationship marketing", Journal of Marketing, Vol. 58 (3) , pp: 20-38.

[8] Shynkarenko VG \& Fedotova IV, Relationship Marketing of the MTE with main partners, KhNAHU, Kharkiv, (2012).

[9] Gummesson E, Total Relationship Marketing; Rethinking Marketing Management: From 4Ps to $30 \mathrm{Rs}$, Woburn, MA, London, (2001).

[10] Ritter T, Wilkinson IF \& Johnston WJ (2004), "Managing in complex business networks", Industrial Marketing Management, №33 (3),- $\quad$ pp.: 175-183, http://doi.org/10.1016/j.indmarman.2003.10.016.

[11] Kushch SP \& Afanasiev AA (2004), "Marketing aspects of the development of intercompany networks: Russian experience", Russian Management Journal, No. 1, pp: 33-52.

[12] Isaeva E.V. Methodology of forming of relationships in small business, NPK "Rost”, St. Petersburg, (2010)

[13] Zineldin M., "IT and Total Relationship Management (TRM) a new marketing management perspective", (2003), available online: http://tvvlibrary.narod.ru/papers/2003/05.htm\#_ftn1.

[14] Gillett AG (2016), "Multiple relationships with multiple stakeholders: the scope of relationship marketing for public services", Journal of Services Research, No.16 (2), pp: 1-28.

[15] Thomas J Kull, Josip Kotlar \& Martin Spring, (2018), "Small and Medium Enterprise Research in Supply Chain Management: The Case for Single-Respondent Research Designs", Journal of Supply Chain Management, Vol. 54, Iss. 1, pp; 23-34 http://doi.org/10.1111/jscm.12157.

[16] Anuja Agarwal, Deepali Sing \& Arun Kumar Agariya (2017), "What Really Leads to Partner Relationship Management? A Review of Literature", Journal of Relationship Marketing, Vol. 16, Is. 4, pp: 245-285, https://doi.org/10.1080/15332667.2017.1349557

[17] Beer S., Brain of the Firm, 2nd ed., John Wiley \& Sons, Chichester, UK, (1994).

[18] J. Peres Rios (2010), "Models of organizational cybernetics for diagnosis and design”, Kybernetes, Vol. 39, №9/10, pp: 1529-1550, http://doi.org /10.1108/03684921011081150.

[19] Puche J, Ponte Blanco B, Costas J, Pino R \& D De la Fuente (2016), "Systemic approach to supply chain management through the viable system model and the theory of constraints", Production Planning \& Control, Vol. 27 (5), pp: 421-430, http://doi.org/10.1080/09537287.2015.1132349.

[20] Shynkarenko VG (2013), "Object of an enterprise marketing activity", Economocs of the transport complex, Vol. 22, pp: 82-97.

[21] John P. van Gigch, System Design Modeling and Metamodeling, Plenom press, New York \& London, (1991), https://doi.org/10.1002/sres.3850090305.

[22] Pishchukhin AM \& Pishchukhina TA (2013), "The Control Simulation of the Enterprise on the Basis Metasystem Approach", Universal Journal of Control and Automation, Vol. 1 (4), pp: 98-102, https://doi.org/10.13189/ujca.2013.010402.

[23] Karpov A.V., Psychology of consciousness. Meta-system approach, Publishing House RAO, Moscow, (2011). 